\title{
HUNECKE, Volker, Der venezianische Adel am Ende der Republik 1646-1797. Demographie, Familie, Haushalt
}

\section{Christophe Duhamelle}

\section{OpenEdition}

\section{Journals}

Édition électronique

URL : http://journals.openedition.org/ifha/1528

DOI : 10.4000/ifha.1528

ISSN : 2198-8943

Éditeur

IFRA - Institut franco-allemand (sciences historiques et sociales)

Référence électronique

Christophe Duhamelle, «HUNECKE, Volker, Der venezianische Adel am Ende der Republik 1646-1797. Demographie, Familie, Haushalt », Revue de l'IFHA [En ligne], Date de recension, mis en ligne le 01 janvier 1997, consulté le 22 septembre 2020. URL : http://journals.openedition.org/ifha/1528 ; DOI : https:// doi.org/10.4000/ifha. 1528

Ce document a été généré automatiquement le 22 septembre 2020.

(C)IFHA 


\title{
HUNECKE, Volker, Der venezianische Adel am Ende der Republik 1646-1797. Demographie, Familie, Haushalt
}

\author{
Christophe Duhamelle
}

1 Dès le XVIIIe s., l'évolution du patriciat a tenu une grande part dans la fascination envers la »décadence vénitienne«. En 1962, J.C. Davis lui consacra un beau livre que l'ouvrage de V.H. ne rend pas obsolète, mais qu'il parvient à préciser et enrichir dans le domaine de la démographie. La démarche de V.H. se distingue en effet par l'usage qu'il fait des registres paroissiaux, plus riches que le "Livre d'Or" utilisé jusque là. Il peut ainsi offrir une image globale de tous les patriciens, et montrer qu'une proportion croissante de mariages ne sont pas déclarés au registre officiel du patriciat, interdisant ainsi aux descendants tout accès au Grand Conseil. V.H. récuse donc définitivement toute idée de "suicide démographique« du patriciat vénitien: la fécondité reste forte et la nuptialité constante au XVIIIe s., si bien que l'extinction des familles progresse selon un rythme inférieur à celui que l'on rencontre pour certaines autres noblesses. Si l'évolution du patriciat présente bien des aspects néfastes, c'est en d'autres domaines. La noblesse vénitienne, tout d'abord, est une de celles qui répugnent le plus à s'ouvrir et à se renouveler. En outre, le grand tournant du XVIe s. - repli sur la richesse foncière et introduction du fidéicommis - entraîne une valorisation de la cohérence patrilinéaire des patrimoines, de leur indivision, et donc du mariage unique. La règle de la primogéniture n'est en revanche pas adoptée: la soumission à la volonté de la Casa, marquée par le maintien d'une communauté des frères (la Fraterna) est d'autant plus forte. Mais le mariage unique par fratrie expose les lignées au danger constant de la mortalité ou de la stérilité et représente un risque dont V.H. pense qu'il est sous-estimé par les familles. En ce sens, le cas vénitien, avec ses particularités, s'inscrit dans l'évolution plus large des aristocraties européennes.

2 Cette discipline est cependant plus rigide - et les risques plus grands - lorsque la Casa est riche. Comme, d'autre part, ce système réduit les transferts cognatiques de richesses, le patriciat tend à se diviser entre une minorité opulente (l'examen des 
domesticités le montre) et un nombre croissant de patriciens "plébéiens«, moins enclins à préserver l'intégrité du corps et contestant au XVIIIe s. leur exclusion de fait de la vie publique. V.H. voit dans cette évolution la cause principale des dysfonctionnements croissants du système politique vénitien. Plus soucieuses de leur perpétuation matérielle - au risque de perpétuer le nom plus que le sang - que de la pérennisation politique d'une aristocratie large et homogène, les familles du patriciat ont ainsi préparé leur propre perte sans qu'il soit besoin pour l'expliquer de recourir à la »décadence morale« ou aux ravages de la syphilis.

3 Dérd parfois rebutant, cet ouvrage révèle progressivement une réelle richesse et de solides aperçus sur l'évolution - pas uniquement démographique - de l'aristocratie pas seulement vénitienne.

4 Christophe DUHAMELLE 